\title{
Metastasis to the Glans Penis: An Unusual Site of Rectal Cancer Recurrence
}

\author{
Metástase da Glande Peniana: Uma Localização Invulgar para Recorrência de \\ Carcinoma do Recto
}

Beatriz NUNES $\rrbracket^{1}$, Margarida MATIAS ${ }^{2}$, António ALVES ${ }^{3}$, Marília JORGE$^{1}$

Acta Med Port 2015 Jul-Aug;28(4):525-527

\section{ABSTRACT}

Secondary malignancy of the penis is a rare clinical condition, often associated with disseminated genitourinary malignancies. The prognosis is poor and the treatment options include penectomy, local surgical excision, radiation therapy, chemotherapy and supportive therapy. Neither of these therapeutic options lead to superior treatment outcomes in the literature. The authors report the case of a 66 year-old man with a metastasis to the glans penis from a rectal adenocarcinoma, diagnosed two years after radical treatment for primary disease. The patient underwent palliative treatment with radiotherapy and chemotherapy, remaining asymptomatic and disease-free at one year follow-up. Close follow-up of patients with history of rectal adenocarcinoma is very important. Radiochemotherapy is a feasible and effective therapeutic option for penile metastasis, addressing both disease control and symptomatic improvement.

Keywords: Neoplasm Metastasis; Penile Neoplasms/secondary; Radiotherapy; Rectal Neoplasms.

\section{RESUMO}

A doença secundária do pénis é uma situação clínica frequentemente associada a doença disseminada e as localizações mais comuns são os órgãos genito-urinários. O prognóstico é mau e as opções de tratamento incluem: penectomia; excisão local; radioterapia; quimioterapia; terapêutica de suporte. Apesar das várias terapêuticas existentes, nenhuma na literatura é apontada como superior às restantes. Os autores documentam o caso de um doente de 66 anos com metástase da glande peniana em contexto de adenocarcinoma do recto, diagnosticada dois anos após o tratamento da doença primária. O doente foi submetido a tratamento paliativo com radio-quimioterapia e permanece assintomático e livre de doença após um ano de seguimento. $\mathrm{O}$ follow-up apertado dos doentes com neoplasia do recto é mandatório. A radio-quimioterapia é uma abordagem válida, com bom controlo da doença e melhoria sintomática. Palavras-chave: Metástases; Neoplasias do Pénis/secundária; Neoplasias do Recto; Radioterapia.

\section{BACKGROUND}

The metastatic involvement of the penis is a rare condition, with less than 400 cases reported in literature. ${ }^{1}$ In $64 \%$ of the cases, genito-urinary organs (prostate and bladder) are the primary sites of origin. ${ }^{2}$

A penile nodule or mass, priapism, penile pain, urinary retention and hematuria are frequent presenting symptoms, even though no pathognomonic clinical features exist. ${ }^{3,4}$

The authors present a case of metastasis to the glans

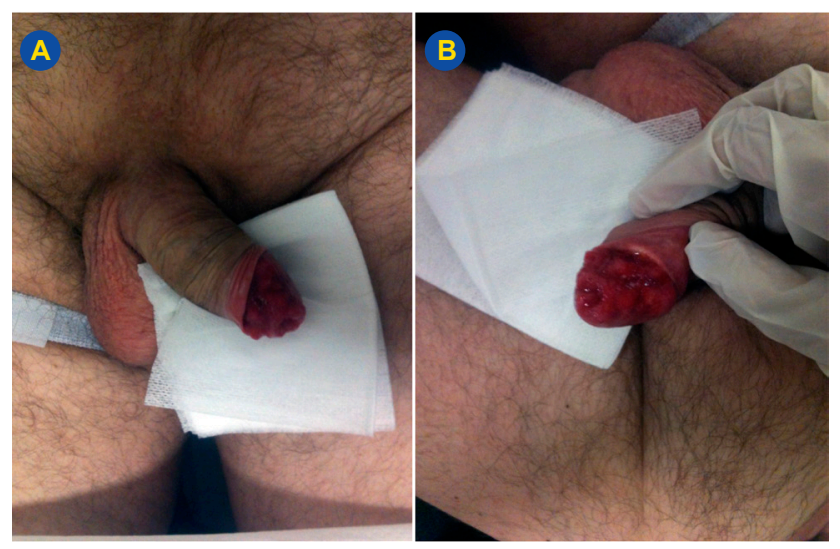

Figure 1 - Erythematous ill-defined infiltrating plaque with an irregular surface and hard consistency occupying the right half of the penis secondary to a rectal adenocarcinoma, diagnosed 2 years after abdominoperineal resection.

\section{CASE PRESENTATION}

A 63-year-old man with a personal history of tobacco consumption (40 pack-year), total prostatectomy for benign prostatic hypertrophy, presented with diarrhea, rectorrhagia, and weigh loss (7 kg in 7 months). Colonoscopy showed an ulcerated lesion of the distal rectum and histologic evaluation of the tumor biopsy revealed a moderately

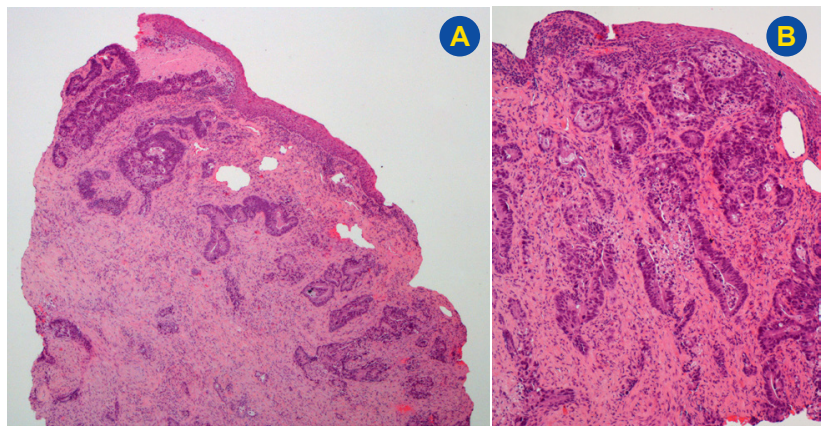

Figure $2-\mathrm{H} \& \mathrm{E}$, Histological section of the glans penis showing invasive adenocarcinoma (A - 40x; B - 100x) glans penis (pretreatment)

1. Serviço de Radioterapia. Hospital de Santa Maria. Centro Hospitalar Lisboa Norte. Lisboa. Portugal.

2. Serviço de Oncologia Médica. Hospital de Santa Maria. Centro Hospitalar Lisboa Norte. Lisboa. Portugal.

3. Serviço de Anatomia Patológica. Hospital de Santa Maria. Centro Hospitalar Lisboa Norte. Lisboa. Portugal.

$\triangle$ Autor correspondente: Beatriz Nunes. bmariamatosn@gmail.com

Recebido: 28 de Agosto de 2014 - Aceite: 01 de Junho de 2015 | Copyright @ Ordem dos Médicos 2015 

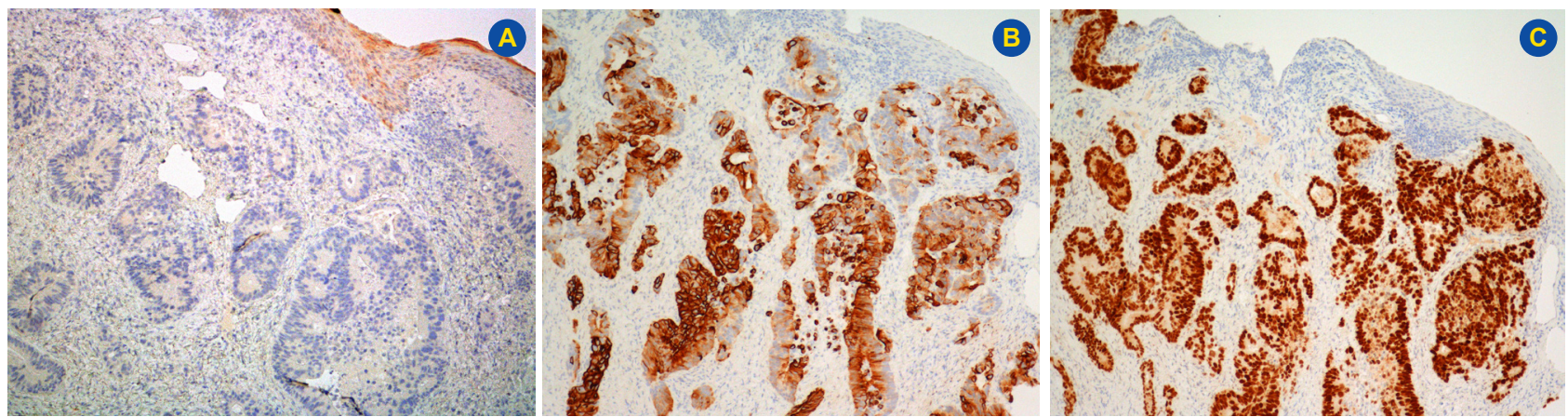

Figure 3 - Immunohistochemical staining of the metastatic adenocarcinoma showing negativity to cytokeratin 7 (A - $100 \mathrm{x}$ ) and immunoreactivity to cytokeratin $20(B-100 x)$ and CDX2 $(C-100 x)$. The complete immunohistochemical study showed positivity for cytokeratins AE1/AE3, CK20, CDX2, villin, $\beta$-catenin and carcinoembryonic antigen and negativity for CK7, 34ßE12, PSA and TTF1.

differentiated adenocarcinoma. After abdominopelvic computed tomography (CT) and pelvic magnetic resonance imaging (MRI), the rectal adenocarcinoma was staged as a cT3N+M0, according to the TNM Classification of Malignant Tumours (TNM). ${ }^{5}$ Neoadjuvant treatment with 3D conformal external radiotherapy (pelvic total dose of 50.4 Gy in 28 fractions, four-field technique) and concomitant capecitabine $\left(850 \mathrm{mg} / \mathrm{m}^{2}\right.$, twice a day, 5 days/week), was performed from July to August 2011. In October 2011, the patient underwent abdominoperineal resection and pathological examination was consistent with ypT3N1. There were several post-operative complications, including surgical repair of a prostatic-cutaneous fistula. No adjuvant chemotherapy was performed.

A skin lesion on the glans was noted on January 2013, evolving with progressive growth and spontaneous bleeding. Clinically, an erythematous ill-defined infiltrating plaque with an irregular surface and hard consistency occupying the right half of the glans was observed (Fig. 1). Histology and immunohistochemistry confirmed the clinical hypothesis of a metastasis to the glans penis of an adenocarcinoma with colorectal origin (Fig.s 2 and 3 ).

The patient underwent 3D conformal external radiotherapy of the penile lesion (total dose of $30 \mathrm{~Gy}$ in 10 fractions, one direct field technique with electrons) (Fig. 4) with concomitant capecitabine $(825 \mathrm{mg} / \mathrm{m} 2$, twice a day, 5 days/week). There were no reported side effects and complete response of penile lesion occurred.

Chest, abdominal and pelvic post-treatment reevaluation CT scans were unremarkable. The patient remains asymptomatic and disease-free at 1 year follow-up (Fig. 5).

\section{DISCUSSION}

In spite of the rich vascularization and extensive communication between the penis and the neighboring organs, penile metastatic lesions are rare. ${ }^{2}$

Various pathways of metastases to the penis have been suggested: retrograde venous route, retrograde lymphatic
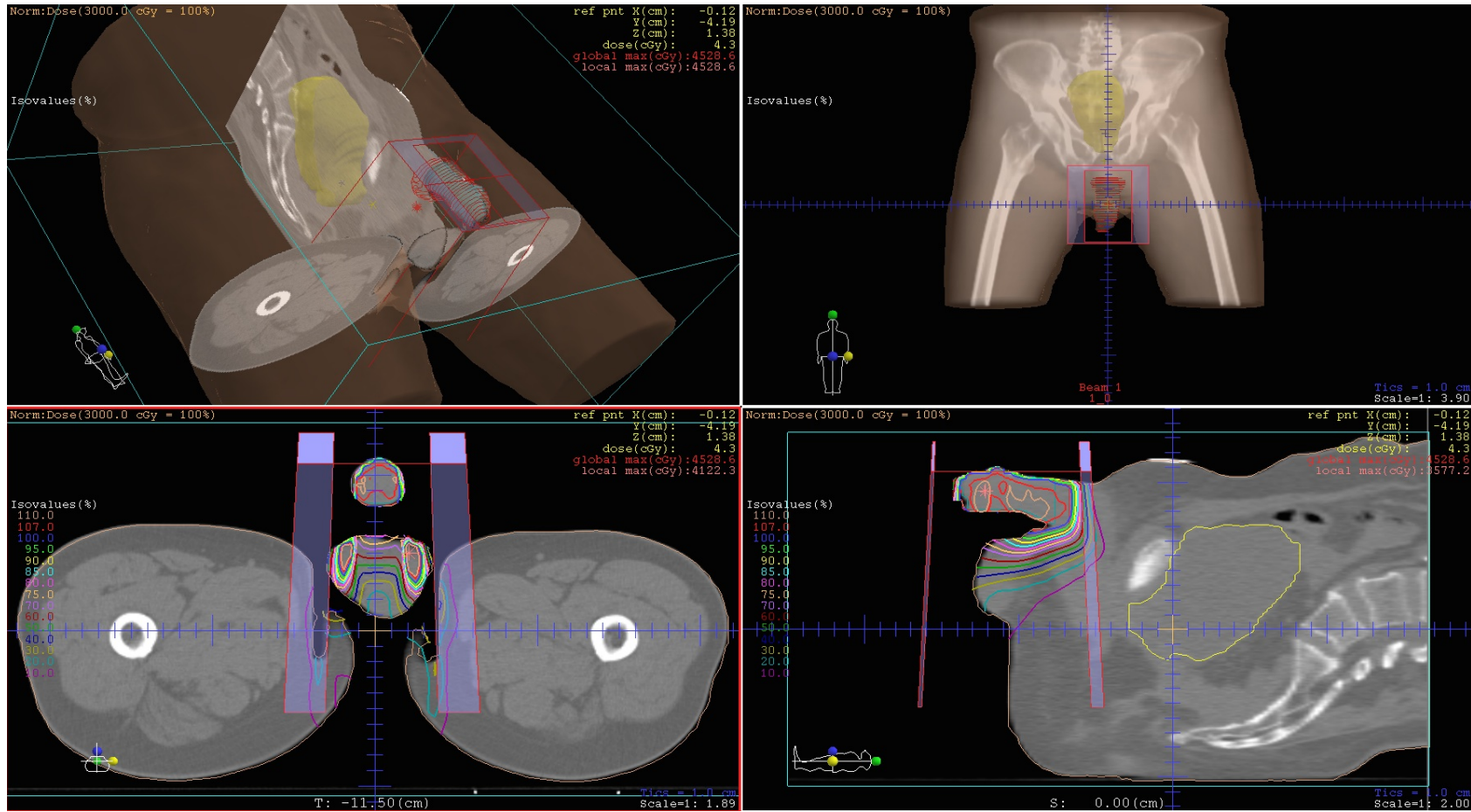

Figure 4 - Map of calculated doses for a 3D conformal external treatment (one direct field technique with electrons) and 3D reconstructions 

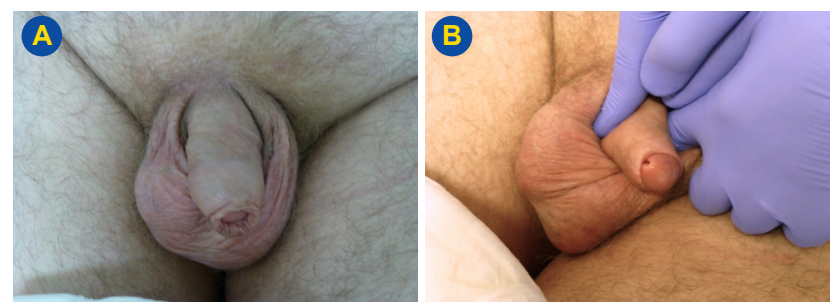

Figure 5 - Glans penis six months after treatment, with no evidence of disease

route, arterial spread, arterial extension, direct extension and surgical instrumentation. Retrograde venous flow from the pudendal venous system onto the dorsal venous system of the penis, which provides routes for easy transportation of malignant cells, is considered the most likely mechanism. ${ }^{2,6}$

Eberth reported the first case of secondary penile malignancy in 1870 and almost 400 cases were documented ever since. ${ }^{1} \mathrm{New}$ data have recently revealed prostate and bladder as the most common primary sites. Other primary locations are rectum, kidney, colon and testes. ${ }^{2}$

Penile involvement is usually associated with disseminated disease and generally predicts a poor prognosis. ${ }^{7,8}$ Nevertheless, some authors have reported long survival cases. In 1961, Abeshouse ${ }^{9}$ documented two patients surviving over nine years after their cancer diagnosis - in one case, the metastasis to the glans penis was treated with low dose rate brachytherapy and, in the other one, with surgical excision and adjuvant external radiotherapy.

Most cases present clinically with a nodule/mass or induration of penis; in $40 \%$ of patients, priapism is also pointed as a prominent feature. ${ }^{2}$

A suspected penile metastasis should be differentiated from primary penile cancer, chancre, primary syphilis, chancroid, condylomata acuminata, non-tumorous priapism, Peyronie's disease, tuberculosis and other inflammatory diseases. ${ }^{2,7}$

For the exact diagnosis, an incisional or fine-needle aspiration biopsy for pathological examination is required. Ultrasonography, CT, MRI and positron emission tomography are useful noninvasive methods for the metastatic disease

\section{REFERENCES}

1. Pierro A, Cilla S, Digesù C, Morganti AG.Penile metastases of recurrence prostatic adenocarcinoma without PSA level increase: a case report. J Clin Imaging Sci. 2012;2:44.

2. Cherian J, Rajan S, Thwaini A, Elmasry Y, Shah T, Puri R. Secondary penile tumors revisited. Int Semin Surg Oncol. 2006;3:33.

3. Kumar P, Newland JR. Metastatic carcinoma of the penis. J Natl Med Assoc. 1980;72:55-8.

4. Ketata S, Boulaire J, Soulimane B, Bargain A. Metachronous metastasis to the penis from a rectal adenocarcinoma. Clin Colorectal Cancer. 2007;6:657-9.

5. Edge S, Byrd DR, Compton CC, Fritz AG, Greene FL, Trotti A editors. evaluation and restaging. ${ }^{6}$

The choice of treatment is greatly influenced by the performance status and primary cancer stage, but frequently has a palliative intention. Treatment options include penectomy, local surgical excision, radiation therapy, chemotherapy and supportive therapy. Neither of these therapeutic options lead to superior treatment outcomes in the literature. ${ }^{4}$

\section{TAKE HOME MESSAGES}

- Penile metastases are rare, and colorectal cancer is an infrequent primary source.

- A close follow-up of colorectal cancer patients is crucial.

- Biopsy of suspicious lesions is mandatory, especially in infrequent recurrence locations like the glans penis.

- The appropriate treatment depends on the exact histological diagnosis.

- Radiochemotherapy is a feasible and effective therapeutic option for penile metastasis of colorectal origin, avoiding more aggressive surgical approaches.

\section{PROTECTION OF HUMANS AND ANIMALS}

The authors declare that the study was approved by the Ethics Committee of the Hospital and that the described procedures followed the regulations established by the Clinical Research and Ethics Committee and to the Helsinki Declaration of the World Medical Association.

\section{DATA CONFIDENTIALITY}

The authors declare that they followed the protocols in use at their working center regarding patient's data publication.

\section{CONFLICTS OF INTEREST}

The authors declare that there are no conflicts of interest.

\section{FUNDING SOURCES}

No subsidies or grants contributed to this work.

AJCC Cancer Staging Manual. $7^{\text {Th }}$ ed. Chicago: Springer-Verlag. 2010. 6. Yildirim M, Coskun A, Pürten M, Oztekin O, Ilhan E. A clinical case of the penile metastasis from the rectal carcinoma. Radiol Oncol. 2010;44:1213.

7. Park J, Lee W, Kang MK, Park SY. Priapism secondary to penile metastasis of rectal cancer. World J Gastroenterol. 2009;15:4209-11.

8. Kimura $Y$, Shida D, Nasu K, Matsunaga H, Warabi M, Inoue S. Metachronous penile metastasis from rectal cancer after total pelvic exenteration. World J Gastroenterol. 2012;18:5476-8.

9. Abeshouse BS, Abeshouse GA. Metastatic tumours of the penis: A review of the literature and a report of two cases. J Urol.1961;86:99-122. 


\section{Metastasis to the Glans Penis: An Unusual Site of Rectal Cancer Recurrence}

Acta Med Port 2015:28:525-527

Publicado pela Acta Médica Portuguesa, a Revista Científica da Ordem dos Médicos

Av. Almirante Gago Coutinho, 151

1749-084 Lisboa, Portugal.

Tel: +351218428 215

E-mail: submissao@actamedicaportuguesa.com

www.actamedicaportuguesa.com

ISSN:0870-399X | e-ISSN: 1646-0758

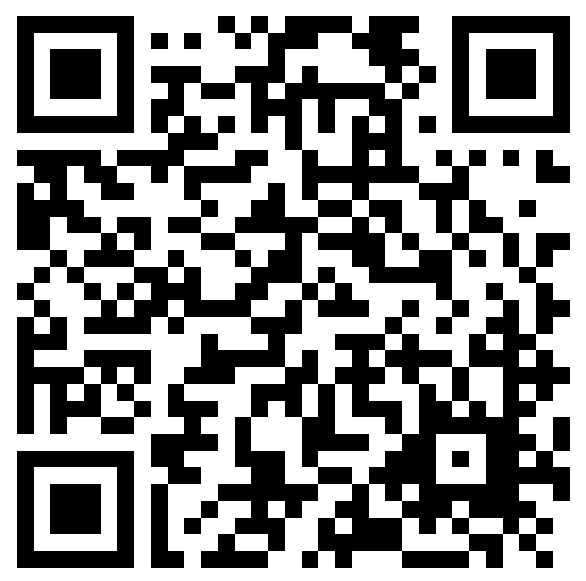

